\title{
Self-management of fatigue in rheumatoid arthritis: a randomised controlled trial of group cognitive-behavioural therapy
}

\author{
Sarah Hewlett, ${ }^{1,2}$ Nick Ambler, ${ }^{3}$ Celia Almeida, ${ }^{1}$ Alena Cliss, ${ }^{1}$ Alison Hammond, ${ }^{4}$ \\ Karen Kitchen, ${ }^{2}$ Bev Knops, ${ }^{3}$ Denise Pope, ${ }^{2}$ Melissa Spears, ${ }^{5}$ Annette Swinkels, ${ }^{6}$ \\ Jon Pollock ${ }^{7}$
}

\begin{abstract}
Additional data are published online only. To view these files please visit the journal online (http://ard.bmi.com)
\end{abstract}

${ }^{1}$ Department of Nursing and Midwifery, University of the West of England, Bristol, UK ${ }^{2}$ Academic Rheumatology, University Hospitals Bristol, Bristol, UK

${ }^{3}$ Pain Management Centre Frenchay Hospital, Bristol, UK ${ }^{4}$ Centre for Health, Sport and Rehabilitation Research, University of Salford, Salford, UK

${ }^{5}$ School of Social and Community Medicine, University of Bristol, Bristol, UK ${ }^{6}$ Department of Allied Health Professions, University of the West of England, Bristol, UK DDepartment of Health and Applied Social Studies, University of the West of England, Bristol, UK

\section{Correspondence to} Sarah Hewlett, Academic Rheumatology Unit, Bristol Royal Infirmary, Bristol BS2 8HW, UK ;

Sarah.Hewlett@uwe.ac.uk

Accepted 31 March 2011

\begin{abstract}
Objectives To investigate the effect of group cognitive behavioural therapy (CBT) for fatigue self-management, compared with groups receiving fatigue information alone, on fatigue impact among people with rheumatoid arthritis (RA).

Methods Two-arm, parallel randomised controlled trial in adults with $R A$, fatigue $\geq 6 / 10$ (Visual Analogue Scale (VAS) 0-10, high bad) and no recent change in RA medication. Group CBT for fatigue self-management comprised six (weekly) $2 \mathrm{~h}$ sessions, and consolidation session (week 14). Control participants received fatigue self-management information in a $1 \mathrm{~h}$ didactic group session. Primary outcome at 18 weeks was the impact of fatigue measured using two methods (Multi-dimensional Assessment of Fatigue (MAF) 0-50; VAS 0-10), analysed using intention-to-treat analysis of covariance with multivariable regression models.
\end{abstract}

Results Of 168 participants randomised, 41 withdrew before entry and 127 participated. There were no major baseline differences between the 65 CBT and 62 control participants. At 18 weeks CBT participants reported better scores than control participants for fatigue impact: MAF 28.99 versus 23.99 (adjusted difference $-5.48,95 \% \mathrm{Cl}-9.50$ to $-1.46, \mathrm{p}=0.008$ ); VAS 5.99 versus 4.26 (adjusted difference $-1.95,95 \% \mathrm{Cl}-2.99$ to $-0.90, p<0.001)$. Standardised effect sizes for fatigue impact were MAF 0.59 (95\% Cl 0.15 to 1.03$)$ and VAS 0.77 (95\% Cl 0.33 to 1.21), both in favour of CBT. Secondary outcomes of perceived fatigue severity, coping, disability, depression, helplessness, self-efficacy and sleep were also better in CBT participants.

Conclusions Group CBT for fatigue self-management in RA improves fatigue impact, coping and perceived severity, and well-being.

Trial registration: ISRCTN 32195100

\section{INTRODUCTION}

Rheumatoid arthritis (RA) is a systemic, inflammatory condition causing synovitis in multiple joints, pain, joint destruction and disability. ${ }^{1}$ Treatment comprises medication to control inflammation, and multidisciplinary team interventions to reduce symptoms and maximise self-management. ${ }^{2} 3$ Patients highlight fatigue as a major concern, ${ }^{4}$ as important as pain, ${ }^{5-8}$ overwhelming, unmanageable and ignored by clinicians. ${ }^{9-11}$ Significant fatigue occurs in up to $70 \%$ of patients with RA, can be as severe as chronic fatigue syndrome, predicts quality of life and is as hard to cope with as pain. ${ }^{12-16}$ The highlighting of fatigue as an unmet concern by patients with RA led to international consensus that fatigue must now be evaluated in all RA clinical trials. ${ }^{17}$

RA pharmacological treatments reduce but do not resolve fatigue, and associations between RA fatigue and measures of inflammation, clinical or psychological health are only moderate. ${ }^{18} 19$ Fatigue is likely to have complex, multicausal pathways comprising varying combinations of clinical (inflammation, pain, disability) and psychosocial factors (mood, beliefs, coping, behaviours), ${ }^{13}$ 19-23 implying that effective fatigue self-management strategies are critical. Enabling self-management for people with long-term conditions is a government target $^{24}$ and RA guidelines recommend support for fatigue. ${ }^{2}{ }^{3}$ Many rheumatology teams provide general self-management education, ${ }^{25}$ but with no systematic review of RA fatigue interventions, clinicians are uncertain how to help. ${ }^{26}$

Multiple sclerosis fatigue was improved by a fatigue self-management programme of individual cognitive behavioural therapy (CBT). ${ }^{27} \mathrm{CBT}$ deals with links between thoughts and feelings that may drive behaviours, and uses cognitive restructuring to help patients make behavioural changes. ${ }^{28}$ For example, thoughts that tasks must be done perfectly, with feelings of failure if they are not, may drive excessive work patterns, leading to fatigue. In CBT, core self-management skills of problem-solving and goal-setting, and peer role models (social cognition theory, SCT) enhance self-efficacy, or confidence that you can do something to make a difference. $^{29}$ A systematic review of general selfmanagement programmes in rheumatic diseases recommends that they incorporate SCT or CBT. ${ }^{25}$ A randomised controlled trial (RCT) of 16 h group (SCT) education for patients and partners, covered comprehensive topics, but not fatigue specifically. ${ }^{30}$ Perceived fatigue improved in patients attending alone, but increased in those accompanied by partners. There were no other clinical or psychological benefits and the study was restricted to patients with partners. An RCT of $22 \mathrm{~h}$ group (SCT) CBT covered comprehensive topics, fatigue and practice (eg, exercises, tai chi). ${ }^{31}$ Fatigue severity, pain, function and mood improved, but the study was restricted to patients with mild/moderate disability. In an RCT of $11 \mathrm{~h}$ individual CBT, participants selected two of four modules, with fatigue as one option. Fatigue and depression improved but no online under the BMJ Journals unlocked scheme, see http:// ard.bmj.com/info/unlocked.dtl 
other clinical or psychological outcomes, and the study was restricted to people with early RA in psychological distress. ${ }^{32}$

Given that RA fatigue is not strongly associated with disability, disease duration or distress ${ }^{19}$ and occurs in at least $70 \%$ of patients, self-management interventions should target the broad RA population. Furthermore, as RA fatigue affects quality of life, ${ }^{9-11} 1415$ an intervention that changes fatigue impact might be expected to change wider well-being. The aim of this study, therefore, was to test, in an inclusive cohort, the null hypothesis that there would be no difference in change in fatigue impact between people with RA participating in a group CBT fatigue self-management programme and groups receiving fatigue information alone. Secondary outcomes were perceived fatigue severity, coping and clinical and psychological wellbeing. People can be at different stages of readiness to change behaviour $^{33}$ therefore stage-of-change data were collected for exploratory analysis.

\section{METHODS}

\section{Trial design}

This was a two-centre controlled trial of group CBT for fatigue self-management versus group information (usual care), with balanced randomisation (1:1), conducted in the UK.

\section{Participants}

Inclusion criteria were adults with confirmed $\mathrm{RA}^{34}$ scoring $\geq 6$ for fatigue during the past week (Visual Analogue Scale (VAS), no fatigue-extreme fatigue, 0-10). Exclusion criteria were change in disease-modifying drugs or biological agents within the preceding 24 weeks (glucocorticoids 6 weeks). Participants were recruited from rheumatology departments in two teaching hospitals in Bristol, UK, approached in person (consecutive patients attending clinic) or by letter (via departmental RA databases, randomly mailed in batches of 40). Ethics approval was obtained (North Somerset and South Bristol research ethics committee, P6/Q2006/149), and the study registered (ISRCTN 32195100). Information sheets provided neutral information on the trial arms, and patients gave written informed consent.

\section{Interventions}

The study team developed the CBT intervention from their clinical chronic pain and chronic fatigue syndrome self-management programmes (NA, BK), incorporating experiences of RA fatigue from clinics $(\mathrm{SH})$, self-management programmes $(\mathrm{AH}, \mathrm{DP})$ and patients (patient research partner KK). ${ }^{35}$ The programme was piloted, refined, then co-delivered by clinical psychologist NA and specialist occupational therapist BK, in $6 \times 2 \mathrm{~h}$ sessions (weeks 1-6), with a 1 h consolidation session (week 14). Topics likely to improve fatigue self-management were included (table 1). Thoughts, feelings and behaviours related to fatigue were addressed using Socratic (reflective) questioning and guided discovery to enable patients to work out links themselves. ${ }^{36}$ Problem-solving, goal-setting, self-monitoring of activity/rest and energy management, aimed to help patients turn cognitive and behavioural changes into improved well-being. Goal-setting occupied the second hour of sessions, each clinician taking half the group to help patients set and review personal cognitive or behavioural goals. Programme homogeneity across groups was maintained through standardised topics, tools, metaphors and handouts, delivered by the same clinicians.

The information-only control arm comprised a $1 \mathrm{~h}$ didactic group session delivered by a rheumatology specialist nurse (DP),

Table 1 Cognitive behavioural therapy intervention topics for each session plus supporting materials

\begin{tabular}{|c|c|c|c|}
\hline Week & 1st Hour & Support materials & 2nd Hour \\
\hline 1 & $\begin{array}{l}\text { a) Course purpose and expectations-Why are we here? } \\
\text { b) Establish ground rules } \\
\text { Commitment, confidentiality, homework } \\
\text { c) Validate your fatigue-share and discuss } \\
\text { Fatigue experiences (differentiate from flare) } \\
\text { Self-management strategies and struggles to change }\end{array}$ & $\begin{array}{l}\text { H: Arthritis Research UK booklets } \\
\text { H: Setting our course (groups' ideas) }\end{array}$ & $\begin{array}{l}\text { Energy management } \\
\text { Boom and bust behaviour } \\
\text { Rewards/pitfalls of boom and bust } \\
\text { Prioritise, balance, pace, plan } \\
\text { Barriers to pacing, choices } \\
\text { H: Achieving a balance } \\
\text { H: Activity cycling } \\
\text { T: Energy management diaries }\end{array}$ \\
\hline 2 & $\begin{array}{l}\text { a) What are your priorities for change in your life? } \\
\text { What are your drainers and energisers? } \\
\text { b) Self-sabotage in the course-How might you do that? }\end{array}$ & $\begin{array}{l}\text { T: Wheel of life (priority areas) } \\
\mathrm{H} \text { : Best ways of self-sabotage }\end{array}$ & $\begin{array}{l}\text { Goal setting (in groups of } 3-4 \text { ) } \\
\text { Individual short-/long-term goals } \\
\text { Use peer group for ideas } \\
\text { Contracting }\end{array}$ \\
\hline 3 & $\begin{array}{l}\text { Sleep and rest } \\
\text { How much do we need? Quality vs quantity } \\
\text { Sleep hygiene strategies for individual patients }\end{array}$ & $\begin{array}{l}\text { H: Getting a better night's sleep } \\
\text { T: Sleep diary (if needed) }\end{array}$ & Goal-setting review, new goals \\
\hline 4 & $\begin{array}{l}\text { Stress and relaxation } \\
\quad \text { Personal stressors, physiological reactions to stress } \\
\text { Relaxation rationale and techniques }\end{array}$ & $\begin{array}{l}\mathrm{H}: \text { Effects of stress } \\
\mathrm{H}: \text { Relaxation practice guide } \\
\mathrm{T} \text { : Relaxation CD }\end{array}$ & Goal-setting review, new goals \\
\hline 5 & $\begin{array}{l}\text { Assertiveness } \\
\text { Passive, manipulative, assertive? Which are you? } \\
\text { Other people's reactions to these? } \\
\text { Communicating your needs }\end{array}$ & $\begin{array}{l}\text { M: Cartoon examples } \\
\text { H: Saying 'No' }\end{array}$ & Goal-setting review, new goals \\
\hline 6 & $\begin{array}{l}\text { Reviewing our self-help toolkit, course consolidation } \\
\text { What have you learnt? Review each topic } \\
\text { Dealing with setbacks-what might you do? } \\
\text { Negative self-talk, automatic thoughts and rumination }\end{array}$ & $\begin{array}{l}\text { M: Islands: } \\
\text { Desert island now=passive } \\
\text { Mainland=unrealistic } 100 \% \text { health } \\
\text { Adaptive coping island=realistic (good life despite } \\
\text { rheumatoid arthritis) } \\
\text { M: Fatigue pit: falling in, digging out } \\
\text { H: The pit and tools to dig yourself out } \\
\text { H: Coping with setbacks }\end{array}$ & Goal-setting review, new goals \\
\hline 7 & $\begin{array}{l}\text { Review past } 8 \text { weeks and all topics } \\
\text { How did you get on? } \\
\text { How did you/will you deal with setbacks? } \\
\text { Goal follow-up }\end{array}$ & & \\
\hline
\end{tabular}


based on the Arthritis Research UK leaflets 'Fatigue and RA' and fatigue excerpts from 'Looking after your joints,' freely available in rheumatology clinics. The session covered fatigue symptoms, consequences, causes and self-management suggestions (pacing, planning, stress, sleep). Both arms received the Arthritis Research UK leaflets.

\section{Outcomes}

Fatigue impact at 18 weeks was the primary outcome, assessed by the Multi-Dimensional Assessment of Fatigue scale (MAF, $0-50)^{37}$ and a VAS (no impact-very great impact, 0-10). Secondary outcomes were perceived fatigue severity (no fatigueextreme fatigue), coping (very poorly-very well), pain (no painpain as bad as it could be) and perceived disease activity (doing very well-very badly) measured using VAS (0-10). Disability was measured by the Health Assessment Questionnaire (HAO, $0-3)^{38}$ and Personal Impact HAQ (0-9). ${ }^{39}$ Wider outcomes were measured by the RA Quality-of-Life scale (0-30), ${ }^{40}$ Hospital Anxiety and Depression Scale (0-21), ${ }^{41}$ Arthritis Helplessness Index (5-30), ${ }^{42}$ RA Self-Efficacy scale (RASE, 28-140) ${ }^{43}$ and a sleep quality question (very good, fairly good, fairly bad, very bad), ${ }^{44}$ recoded as a binary variable as numbers were insufficient for analysis. Baseline readiness to make cognitive or behavioural changes was measured using the Arthritis Stages of Change (ASOC) subscales (8-40). ${ }^{33}$ Higher scores always reflect worse health status, except fatigue coping VAS, RASE and ASOC where they reflect stronger beliefs. Outcomes were measured at $0,6,10$ and 18 weeks.

\section{Sample size}

Forty-four patients in each arm were needed to show a difference of $7 \mathrm{MAF}$ points in fatigue impact between trial arms, with $90 \%$ power and estimated SD 10 points (two-tailed significance 0.05 ) (based on unpublished data). No minimal clinically important difference has been published for MAF in RA, but is 5 in lupus. ${ }^{45}$

\section{Randomisation}

The intervention and control sessions were delivered to groups, therefore whenever 12-16 participants had been recruited, project managers (AC, CA) emailed participant codes to epidemiologist JP who performed randomisation off-site, using computer-generated random numbers. Allocation was 1:1 but in the event of an unequal number, the CBT arm received the additional patient. To reduce hospital visits, baseline data were collected immediately before the first CBT or control session (after randomisation).

\section{Blinding}

Delivery methods and the need to encourage participants to make cognitive and behavioural changes, rendered blinding of participants and clinicians impossible. However, all assessments were self-reports using validated measures and analysed blind to allocation (JP).

\section{Statistical methods}

Baseline characteristics were described using means and SDs or numbers and percentages for continuous and categorical variables, respectively. The primary intention-to-treat analysis involved between-arm comparisons for fatigue impact outcome scores (MAF, VAS Fatigue Impact) at 18 weeks, adjusted for respective baseline values. These analyses of covariance were implemented using multivariable linear regression models. Standardised effect sizes for the primary outcome were calculated (adjusted mean difference divided by pooled baseline SD), with $>0.5$ considered a large effect. Secondary sensitivity analyses of primary outcomes were conducted by (1) additional adjustment for any variables displaying imbalance at baseline; (2) fitting multilevel mixed-effects models to investigate any clustering effect from delivery in groups and (3) multiple imputation (MI) techniques to investigate the impact of missing data, based on 20 imputed datasets, with baseline fatigue severity, impact, pain and perceived disease activity added to the imputation model as variables predictive of missingness. ${ }^{46}$ Secondary outcomes were then analysed in the same way. Further analyses using repeated-measures mixed-effects analysis of covariance models examined the effect of interventions over time by including up to three follow-up scores per participant for each primary outcome (MAF, Impact VAS), adjusting for baseline scores. Convergence/divergence between trial arms over time was investigated by including appropriate interaction terms in the model, and the clustering effect of group delivery was again investigated by including group identifier as a third level. All analyses were conducted using Stata version 11.

\section{RESULTS}

Of 1342 individuals invited to participate, 19\% ( $\mathrm{n}=254)$ responded and were eligible, and of these $66 \%(n=168)$ provided verbal consent to participate and were randomised (figure 1). Of the 168 randomised, 24\% ( $n=41)$ withdrew from the trial before providing written consent and baseline data. Therefore a total of 127 participants were allocated to either CBT $(n=65)$ or the control group $(n=62)$. They were contacted for follow-up data at 6,10 and 18 weeks after their intervention started, with 74 and $76(58 \%, 60 \%)$ completing all three follow-ups for MAF and VAS, respectively. The 41 who withdrew had similar characteristics to the 127 who participated for gender $(85.4 \%$ vs $76.2 \%$ female), age (57.6 years vs 59.2 years) and disease duration (14.8 years vs 14.5 years). At baseline, participants reported high levels of fatigue impact and severity, and limited ability to cope with fatigue (table 2). In contrast they reported lower levels of disease activity and pain. Mean scores for contemplating changing behaviour were higher than pre-contemplation. There were similar characteristics across arms, apart from sleep quality, which appeared poorer in CBT participants. Twenty CBT and 20 control subjects $(35.4 \%$ ) had attended a general RA selfmanagement programme an average 4.0 years earlier.

Thirteen control groups were conducted, comprising 2-8 participants (mean 5), with 11 CBT groups, comprising 4-9 participants (mean 6). Of the 65 CBT participants, $66.2 \%$ (43) attended most sessions (30 attended all seven, 13 attended six); 18.5\% (12) attended three to five sessions, largely citing illness if a reason was given for intermittent non-attendance; $15.4 \%$ (10) withdrew after less than three sessions, and where offered, reasons were largely poor health, or lack of interest (2). This was a pragmatic trial offered in addition to usual care, which included medication change. Forty-four (34.6\%) participants had changes to major RA medication during the trial, which was similar between arms (24 (36.9\%) CBT vs 20 (32.3\%) control); 20 (15.7\%) were receiving or started antidepressant drugs ( 9 vs 11 ) and $33.1 \%$ physiotherapy or occupational therapy (20 vs 22).

\section{Primary outcome}

Primary outcome data at 18 weeks were obtained for $65 \%$ (MAF) and $67 \%$ (VAS fatigue impact) of the 127 participants. There 


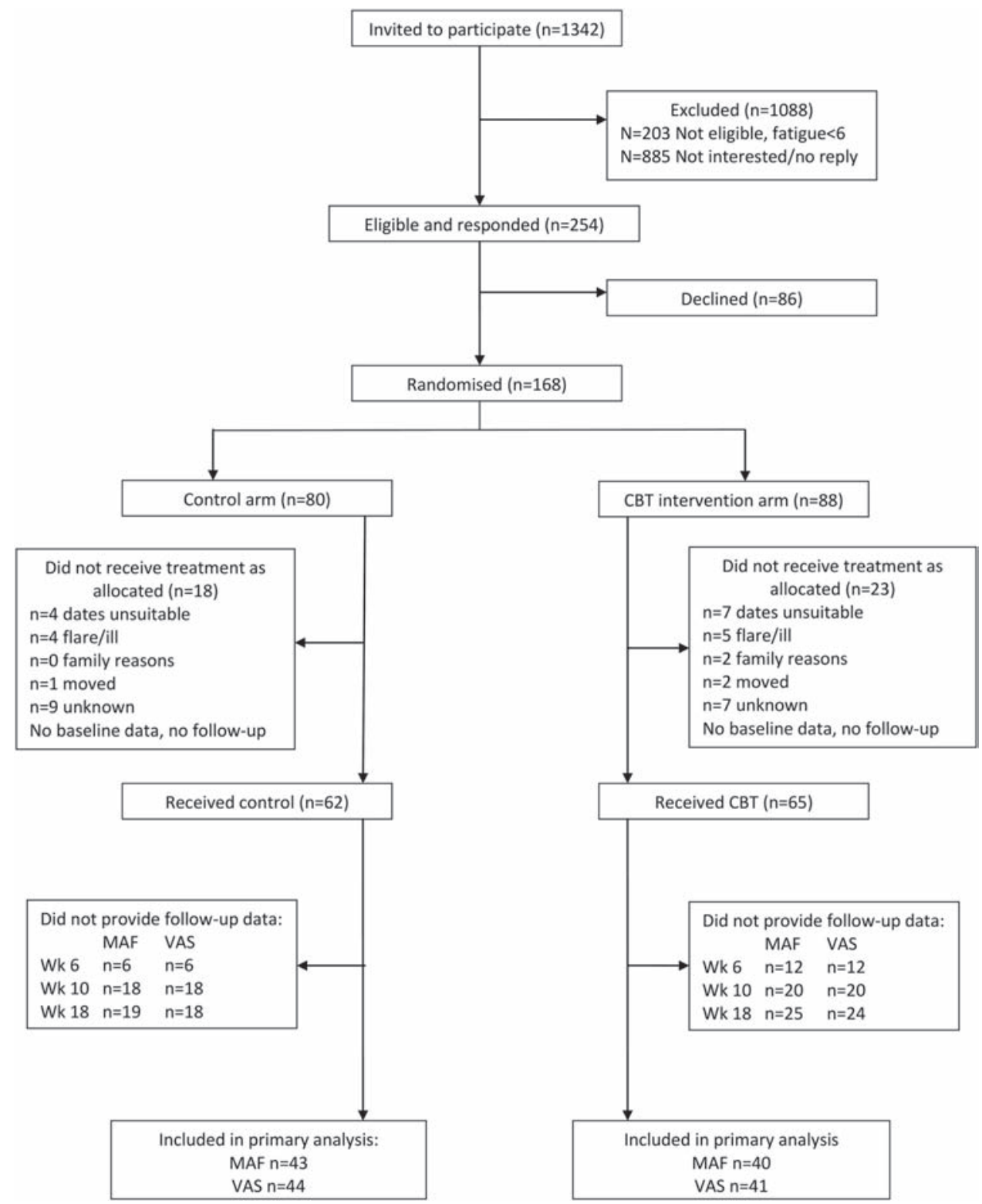

Figure 1 Flow chart of participants. CBT, cognitive behavioural therapy; MAF, MAF, Multi-dimensional Assessment of Fatigue (scale); VAS, Visual Analogue Scale.

was strong evidence of a beneficial effect of CBT at 18 weeks with significant differences between trial arms for fatigue impact (table 3). The standardised effect size for MAF was $0.59(95 \%$ CI 0.15 to 1.03 ) and 0.77 for fatigue impact VAS (95\% CI 0.33 to 1.21) in favour of the CBT intervention. Neither additional adjustment for variables possibly imbalanced at baseline (age, gender, sleep, disease duration and readiness to change), nor inclusion of 'group' using multilevel models made any material difference to the primary outcomes, therefore results from the simple analyses of covariance are presented. Analyses based on MI of missing data resulted in slight attenuation of effects and improvements in precision, but made no material difference to the conclusions drawn from primary analyses. Adjusted treatment differences for MI models were MAF -4.13 (95\% CI -7.86 to $-0.40, \mathrm{p}=0.03)$ and VAS -1.47 (95\% CI -2.39 to $-0.55, \mathrm{p}=0.002)$.

\section{Secondary outcomes}

There was evidence of a beneficial effect of the intervention on fatigue coping and perceived severity (table 4). In addition, there were beneficial effects on disability, depression, helplessness, self-efficacy and sleep. Again, additional adjustment for age, gender, sleep, disease duration, readiness to change or group made no difference. There was no evidence of an intervention effect on perceived disease activity, pain, anxiety, quality of life or disability impact.

\section{Effects over time}

The median number of follow-ups for each person was four, with this being true for $60 \%(n=76)$ of individuals. Repeatedmeasures mixed-effects analyses showed no interaction effects with time, for fatigue impact (MAF $\mathrm{p}=0.68$ for interaction terms; VAS impact $p=0.16$ ) (figure 2). Main effects (average difference across all time points) for CBT versus control were -4.57 for $\operatorname{MAF}(95 \% \mathrm{CI}-6.57$ to $-2.57, \mathrm{p}<0.001)$ and $-1.47(95 \% \mathrm{CI}$ -2.01 to $-0.93, p<0.001)$ for VAS impact.By the end of the main 6 week CBT programme there appeared to be clinical differences emerging between the arms for fatigue and clinical variables, maintained at 10 weeks (online supplementary table 5). These 
Table 2 Baseline summary statistics split by trial arm

\begin{tabular}{|c|c|c|c|}
\hline \multirow[b]{2}{*}{ Variable } & \multicolumn{2}{|l|}{ Trial arm } & \multirow[b]{2}{*}{ Total $(n=126)$} \\
\hline & Control $(n=62)$ & CBT $(n=65)$ & \\
\hline Gender: female, $\mathrm{n}(\%)$ & $44(71)$ & $49(75.4)$ & $93(73.2)$ \\
\hline Age (years) & $58.25(12.0)$ & $61.1(10.5)$ & $59.2(11.3)$ \\
\hline Disease duration (years) & $14.6(10.6)$ & $14.2(11.6)$ & $14.0(11.1)$ \\
\hline \multicolumn{4}{|l|}{ Fatigue measures } \\
\hline Impact, MAF (0-50) & $30.5(9.3)$ & $31.0(9.3)$ & $30.7(9.3)$ \\
\hline Impact, VAS (0-10) & $5.9(2.7)$ & $6.3(2.4)$ & $6.1(2.5)$ \\
\hline Severity, VAS $(0-10)$ & $6.1(2.5)$ & $6.5(2.3)$ & $6.3(2.4)$ \\
\hline Coping, VAS $(0-10)^{*}$ & $6.0(2.3)$ & $5.3(2.4)$ & $5.7(2.4)$ \\
\hline Pain, VAS $(0-10)$ & $4.8(2.4)$ & $4.6(2.5)$ & $4.0(2.5)$ \\
\hline Disease activity, VAS (0-10) & $4.1(2.5)$ & $3.8(2.1)$ & $4.0(2.3)$ \\
\hline Disability, HAO (0-10) & $1.6(0.7)$ & $1.5(0.6)$ & $1.6(0.7)$ \\
\hline Impact disability, PIHAO (0-9) & $3.8(1.9)$ & $3.8(1.7)$ & $3.8(1.8)$ \\
\hline Quality of life, RAOoL (0-30) & $17.6(6.5)$ & $15.6(6.6)$ & $16.6(6.6)$ \\
\hline Anxiety, HADS (0-21) & $9.1(4.8)$ & $8.3(4.6)$ & $8.7(4.7)$ \\
\hline Depression, HADS (0-21) & $7.3(3.9)$ & $6.9(3.4)$ & $7.1(3.7)$ \\
\hline Helplessness, AHI (5-30) & $18.8(5.0)$ & $17.0(4.6)$ & $17.9(4.8)$ \\
\hline Self-efficacy, RASE (28-140)* & $103.5(16.5)$ & $106.1(14.1)$ & $104.8(15.3)$ \\
\hline \multicolumn{4}{|c|}{ Readiness to change, ASOC $(8-40)^{*}$} \\
\hline Pre-contemplation & $18.1(6.2)$ & $18.1(4.7)$ & $18.1(5.4)$ \\
\hline Contemplation & $28.9(6.8)$ & $29.0(5.0)$ & $29.0(6.0)$ \\
\hline Action & $26.7(7.1)$ & $28.3(4.3)$ & $27.5(5.8)$ \\
\hline Maintenance & $25.5(6.2)$ & $25.9(5.1)$ & $25.7(5.7)$ \\
\hline \multicolumn{4}{|c|}{ Fatigue change past week, MAF item $16, \mathrm{n}(\%)$} \\
\hline Decreased & $3(4.9)$ & $2(3.1)$ & $5(4.0)$ \\
\hline Same & $25(41.0)$ & $24(37.5)$ & $49(39.2)$ \\
\hline Up and down & $30(49.2)$ & $31(48.4)$ & $61(48.8)$ \\
\hline Increased & $3(4.9)$ & $7(10.9)$ & $10(8)$ \\
\hline Sleep quality: good, $n(\%)$ & $27(45)$ & $23(37.7)$ & $50(41.3)$ \\
\hline
\end{tabular}

Table 3 Primary outcome scores for fatigue impact at 18 weeks

\begin{tabular}{|c|c|c|c|c|c|c|c|c|}
\hline & \multicolumn{3}{|l|}{ Control } & \multicolumn{3}{|l|}{ CBT } & \multirow{2}{*}{$\begin{array}{l}\text { Adjusted difference* } \\
(95 \% \mathrm{CI})\end{array}$} & \multirow[b]{2}{*}{ p Value } \\
\hline & Baseline & 18 weeks & $\mathbf{n}$ & Baseline & 18 weeks & $\mathbf{n}$ & & \\
\hline Fatigue Impact, MAF (0-50) & $30.46(9.25)$ & $28.99(11.31)$ & 43 & $30.99(9.33)$ & $23.99(10.86)$ & 40 & $-5.48(-9.50$ to -1.46$)$ & 0.008 \\
\hline Fatigue Impact, VAS (0-10) & $5.9(2.71)$ & $5.99(2.72)$ & 44 & $6.29(2.38)$ & $4.26(2.78)$ & 41 & $-1.95(-2.99$ to -0.90$)$ & $<0.001$ \\
\hline
\end{tabular}

Except where indicated otherwise, all values are expressed as mean (SD). Except where indicated otherwise, high scores reflect worse health.

${ }^{*}$ Adjusted for baseline score.

CBT, cognitive behavioural therapy; MAF, Multi-dimensional Assessment of Fatigue (scale); VAS, Visual Analogue Scale.

time points were not tested for statistical significance (potential multiple testing), and as the final booster CBT session occurred at 14 weeks, the primary end point was 18 weeks.

\section{DISCUSSION}

These results indicate an effect of group CBT for fatigue selfmanagement on fatigue impact, coping and perceived severity and a range of clinical and psychological variables. The minimal clinically important difference for VAS fatigue severity is $1,{ }^{47}$ and fatigue impact probably lies within a similar range, implying this mean change (2.03) is clinically relevant. Pain and perceived disease activity were not changed, but their association with fatigue remains unclear ${ }^{19}$ and although fatigued, participants did not report high baseline levels of either.

The study was limited by withdrawal of participants before baseline, many citing unsuitable session dates or flare/illness (none reported being too tired). Baseline data were collected after randomisation, which might potentially have biased responses, but the data showed that groups were well matched. Participants had low baseline scores for pre-contemplating change, suggesting others who are in pre-contemplation might have been less likely to agree to a self-management programme. However, adjusting for readiness to change did not alter the findings. Readiness to change was only measured at baseline, therefore we could not evaluate whether people progressed through stages during the intervention, although related concepts of selfefficacy and helplessness improved. Some participants did not complete all follow-ups but the majority of CBT participants attended all or most sessions, suggesting commitment to the intervention. The impact of missing data, as considered using MIs, is unknown. These may not be missing at random, potentially giving slightly inflated treatment effects. It was not possible to blind participants and staff, but self-report measures were analysed blind to arm allocation. There was no control for the social effects of six group CBT sessions, as it was considered six control sessions giving fatigue information alone would mean 
Table 4 Secondary outcomes at 18 weeks

\begin{tabular}{|c|c|c|c|c|}
\hline Variable & Control (18 weeks) & Intervention (18 weeks) & Adjusted difference* (95\% Cl) & p Value \\
\hline \multicolumn{5}{|l|}{ Fatigue measures } \\
\hline Severity, VAS (0-10) & $6.22(2.63)$ & $4.82(2.54)$ & $-1.56(-2.59$ to -0.54$)$ & 0.003 \\
\hline Coping, VAS $(0-10)^{\dagger}$ & $5.98(2.54)$ & $7.19(1.91)$ & 1.33 (0.37 to 2.30$)$ & 0.007 \\
\hline Pain, VAS (0-10) & $4.86(2.81)$ & $4.06(2.44)$ & $-0.81(-1.84$ to 0.22$)$ & 0.12 \\
\hline Disease activity, VAS (0-10) & $3.99(2.34)$ & $3.17(2.25)$ & $-0.62(-1.48$ to 0.24$)$ & 0.16 \\
\hline Disability, HAO (0-10) & $1.75(0.68)$ & $1.30(0.61)$ & $-0.19(-0.36$ to -0.02$)$ & 0.031 \\
\hline Impact disability, PIHAO (0-9) & $3.71(1.63)$ & $2.97(1.53)$ & $-0.22(-0.72$ to 0.29$)$ & 0.4 \\
\hline Quality of life, RAOoL (0-30) & $14.80(9.97)$ & $11.15(6.65)$ & $-0.48(-3.40$ to 2.45$)$ & 0.75 \\
\hline Anxiety, HADS (0-21) & 7.59 (4.74) & $5.32(4.61)$ & $-0.78(-2.03$ to 0.47$)$ & 0.22 \\
\hline Depression, HADS (0-21) & $7.55(4.51)$ & $4.88(3.66)$ & $-1.98(-3.20$ to -0.75$)$ & 0.002 \\
\hline Helplessness, AHI (5-30) & 18.27 (4.99) & $13.78(4.23)$ & $-3.13(-4.73$ to -1.53$)$ & $<0.001$ \\
\hline \multirow[t]{2}{*}{ Self-efficacy, RASE $(28-140)^{\dagger}$} & $104.16(12.66)$ & $112.12(21.33)$ & 6.74 (0.24 to 13.25$)$ & 0.042 \\
\hline & & & Adjusted $0 \mathrm{R}^{*}(95 \% \mathrm{Cl})$ & \\
\hline Sleep quality: good, n (\%) & $25(56.82)$ & $31(75.61)$ & 0.34 (0.12 to 0.95$)$ & 0.04 \\
\hline
\end{tabular}

Except where indicated otherwise, all values are expressed as mean (SD). Except where indicated otherwise, high scores reflect worse health.

${ }^{*}$ Adjusted for baseline score.

${ }^{\dagger}$ High scores reflect stronger beliefs.

AHI, Arthritis Helplessness Index; HADS, Hospital Anxiety and Depression Scale; HAQ, Health Assessment Questionnaire;

PIHAQ, Personal Impact HAQ; RAQoL, Rheumatoid Arthritis Quality of Life (instrument); RASE, Rheumatoid Arthritis Self-Efficacy

scale; VAS, Visual Analogue Scale.

high attrition. However, studies that have controlled for social effects by matching numbers of group sessions, still show CBT to be superior. ${ }^{31}$ Many participants had medication changes for RA inflammation, in this pragmatic trial reflecting usual clinical practice. However, these changes were not obviously different between arms, and association between inflammation and RA fatigue remains unclear. ${ }^{19}$ Future research should evaluate the longer-term effects of CBT for RA fatigue, cost-effectiveness for this CBT programme versus longer durations ${ }^{30} 31$ and individual versus group $\mathrm{CBT}^{32} 48$

Other self-management interventions based on CBT or SCT have improved fatigue but were tested in restricted RA populations, ${ }^{30-32}$ while this CBT intervention improved fatigue in a broad range of patients with RA experiencing fatigue. Furthermore, findings were not altered when adjusted for age, disease duration, gender or baseline stage of change, suggesting a widely applicable intervention.

This CBT intervention focused entirely on thoughts, feelings, behaviours, personal interactions, stressors and issues likely to have an impact on fatigue, yet demonstrated a wide range of additional clinical and psychological benefits. Such wider benefits were also seen in a general CBT/SCT intervention that dealt with fatigue ${ }^{31}$ but not in two other CBT/SCT interventions. ${ }^{30} 32$ All four interventions have similar theoretical underpinnings, therefore possible reasons for differences in wider outcomes may lie in the populations or outcome measures selected, or the social enhancement of group CBT versus individual CBT or with a partner. ${ }^{30} 32$ This $13 \mathrm{~h}$ group CBT intervention concentrating on fatigue, produced wideranging clinical and psychological benefits similar to those of a broader $22 \mathrm{~h}$ group CBT intervention with a range of topics (including fatigue) and practice sessions. ${ }^{31}$ Concentrating on improving fatigue self-management may lead to improvement in well-being if those broader variables are driven by fatigue. Alternatively, the skills that patients develop to manage fatigue may also be useful in managing mood and thus improve wellbeing. A direct comparison of fatigue-focused versus broader self-management programmes might elucidate potential mechanisms.

During the stressors and communication sessions, patients reported that personal interactions with family can be both supportive and stressful in relation to fatigue. Personal interactions play a role in RA fatigue ${ }^{49}$ and attending groups with a partner increased fatigue. ${ }^{30} \mathrm{CBT}$ is more commonly delivered to individuals, exploring their unique links between thoughts, feelings and behaviours, ${ }^{27} 32$ but this study showed that group CBT can pursue individual goal-setting in subgroups, and still improve fatigue and well-being. In this intervention the size and composition of groups, and interactions between participants varied, yet adjusting for group made no difference to the findings.

This study lends support to the theory that complex interactions between disease, personal context, cognitions and behaviours drive fatigue (and thus its impact), ${ }^{23}$ as a range of health benefits resulted from group CBT for RA fatigue, delivered by $\mathrm{CB}$ therapists. In clinical practice, interventions must be delivered pragmatically and efficiently. Embedding such an intervention within the clinical rheumatology team is essential, given that trained CB therapists are not readily available to most teams, and improving access to psychological therapies is recommended. ${ }^{50} \mathrm{~A}$ developmental project is therefore exploring whether, after brief training in $\mathrm{CB}$ approaches, the usual clinical team could lead this intervention using a detailed manual (leading to a clinical trial).

Acknowledgements The authors thank the trial participants, the rheumatologists who supported recruitment, Arthritis Research UK who funded the study, Dr Alan Montgomery for his statistical support and the reviewers for their advice and comments.

Funding This research was funded by Arthritis Research UK (grant 17340), which had no role in study design or conduct, the preparation of this paper or decision to submit for publication.

Competing interests None.

Contributors SH and NA conceived the original idea, all authors contributed to study design and formed the study team. SH led the study team, supervised the conduct of the trial, analysis and reporting, and drafted the manuscript. NA led the design and delivery of the cognitive behavioural therapy (CBT) intervention, including quality control, reviewing the analysis and reporting. $C A$ and $A C$ were the project managers responsible for study organisation, recruitment, data collection and data entry. AH provided rheumatoid arthritis self-management expertise, contributed to the intervention evaluation and reviewed the analyses. KK participated in and reviewed the pilot of the intervention, and commented on the analysis. BK helped to design the CBT intervention, co-delivered it and contributed to the interpretation of the findings. DP provided rheumatology expertise and designed and delivered the control session. AS contributed to study monitoring, evaluation, analysis review and interpretation. 

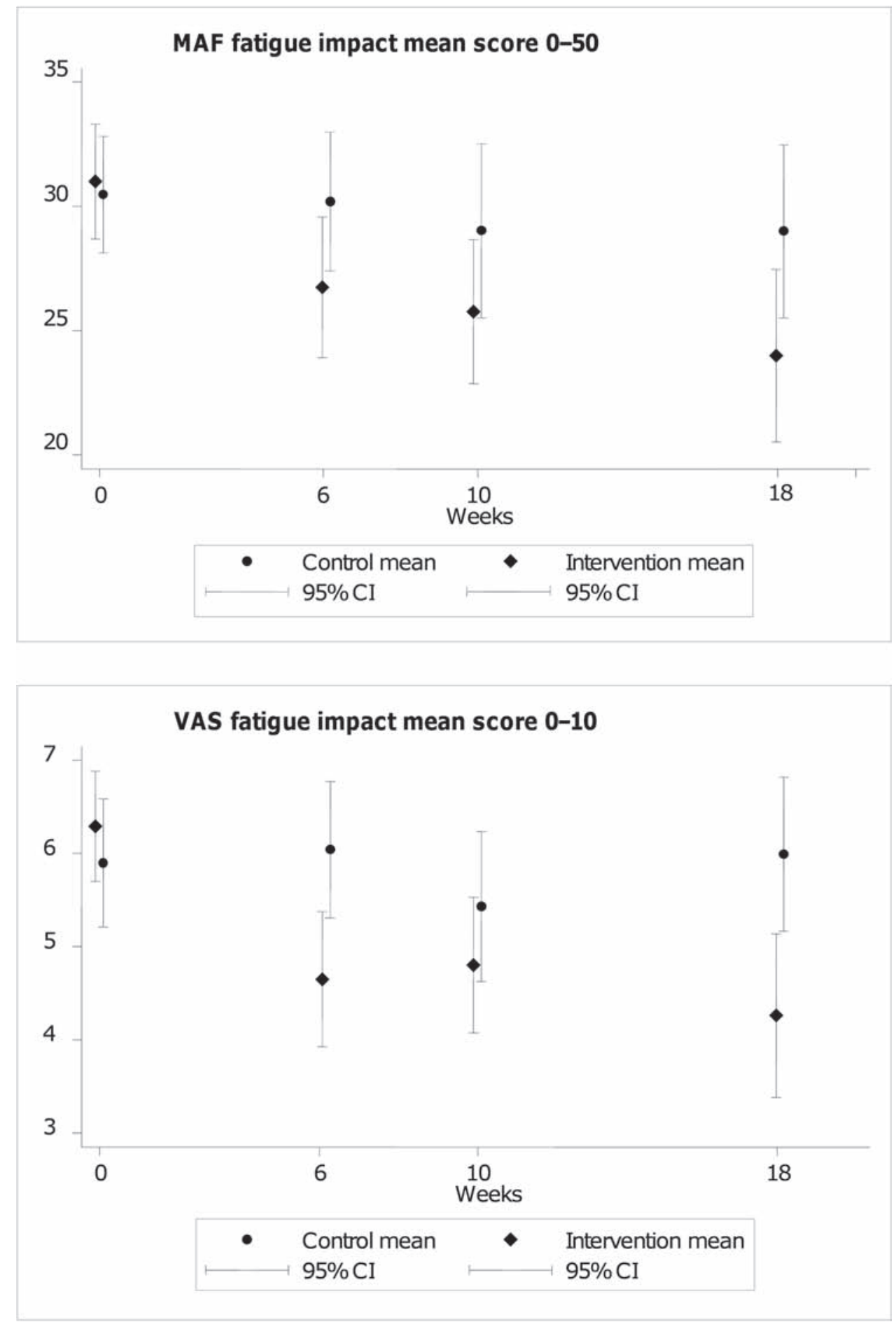

Figure 2 Fatigue impact scores over time. MAF, MAF, Multi-dimensional Assessment of Fatigue (scale); VAS, Visual Analogue Scale.

MS was responsible for data analysis. JP was responsible for randomisation procedures, contributed to the study design, trial analysis and interpretation. All authors contributed to, reviewed and approved the final manuscript. SH, NA and JP are guarantors. Dr Paul Creamer, Dr Val Kyle and Dr Nicky Minaur led recruitment at the second centre.

Ethics approval This study was conducted with the approval of the North Somerset and South Bristol Research ethics committee, Reference P6/02006/149.

Provenance and peer review Not commissioned; externally peer reviewed.

\section{REFERENCES}

1. Scott DL, Steer S. The course of established rheumatoid arthritis. Best Pract Res Clin Rheumatol 2007;21:943-67.
2. Luqmani R, Hennell S, Estrach C, et al. British Society for Rheumatology and British Health Professionals in Rheumatology guideline for the management of rheumatoid arthritis (the first two years). Rheumatology (Oxford) 2006;45:1167-9.

3. Luqmani R, Hennell S, Estrach C, et al. British Society for Rheumatology and British Health Professionals in Rheumatology guideline for the management of rheumatoid arthritis (after the first 2 years). Rheumatology (Oxford) 2009;48:436-9.

4. Carr A, Hewlett S, Hughes R, et al. Rheumatology outcomes: the patient's perspective. J Rheumatol 2003;30:880-3.

5. Hewlett S, Carr M, Ryan S, et al. Outcomes generated by patients with rheumatoid arthritis: how important are they? Musculoskeletal Care 2005;3:131-42.

6. Gossec L, Dougados M, Rincheval N, et al. Elaboration of the preliminary Rheumatoid Arthritis Impact of Disease (RAID) score: a EULAR initiative. Ann Rheum Dis 2009;68:1680-5. 
7. Sanderson T, Morris M, Calnan M, et al. Patient perspective of measuring treatment efficacy: the rheumatoid arthritis patient priorities for pharmacologic interventions outcomes. Arthritis Care Res (Hoboken) 2010;62:647-56.

8. Minnock P, Bresnihan B. Pain outcome and fatigue levels reported by women with established rheumatoid arthritis [abstract]. Arthritis Rheum 2004;50(Suppl):S471 (1198).

9. Hewlett S, Cockshott Z, Byron M, et al. Patients' perceptions of fatigue in rheumatoid arthritis: overwhelming, uncontrollable, ignored. Arthritis Rheum 2005;53:697-702.

10. Repping-Wuts H, Uitterhoeve R, van Riel P, et al. Fatigue as experienced by patients with rheumatoid arthritis (RA): a qualitative study. Int J Nurs Stud 2008;45:995-1002

11. Nikolaus S, Bode C, Taal E, et al. New insights into the experience of fatigue among patients with rheumatoid arthritis: a qualitative study. Ann Rheum Dis 2010;69:895-7.

12. Wolfe F, Hawley DJ, Wilson K. The prevalence and meaning of fatigue in rheumatic disease. J Rheumatol 1996;23:1407-17.

13. van Hoogmoed D, Fransen J, Bleijenberg G, et al. Physical and psychosocial correlates of severe fatigue in rheumatoid arthritis. Rheumatology (Oxford) 2010;49:1294-302.

14. Suurmeijer TP, Waltz M, Moum T, et al. Quality of life profiles in the first years of rheumatoid arthritis: results from the EURIDISS longitudinal study. Arthritis Rheum 2001;45:111-21.

15. Rupp I, Boshuizen HC, Jacobi CE, et al. Impact of fatigue on health-related quality of life in rheumatoid arthritis. Arthritis Rheum 2004:51:578-85.

16. Katz PP. The stresses of rheumatoid arthritis: appraisals of perceived impact and coping efficacy. Arthritis Care Res 1998;11:9-22.

17. Kirwan JR, Minnock P, Adebajo A, et al. Patient perspective: fatigue as a recommended patient centered outcome measure in rheumatoid arthritis. J Rheumatol 2007;34:1174-7.

18. Strand V, Singh JA. Improved health-related quality of life with effective disease-modifying antirheumatic drugs: evidence from randomized controlled trials. Am J Manag Care 2007;13(Suppl 9):S237-51.

19. Hewlett S, Nicklin J, Treharne GJ, . Fatigue in musculoskeletal conditions. Topical Reviews Series 6:1. Arthritis Research UK, 2008. http://www.arthritisresearchuk.org/ files/6641 25022010173830.pdf (accessed 23 September 2010).

20. Pollard LC, Choy EH, Gonzalez J, et al. Fatigue in rheumatoid arthritis reflects pain, not disease activity. Rheumatology (Oxford) 2006;45:885-9.

21. Goodchild CE, Treharne GJ, Booth DA, et al. Daytime patterning of fatigue and its associations with the previous night's discomfort and poor sleep among women with primary Sjögren's syndrome or rheumatoid arthritis. Musculoskeletal Care 2010;8:107-17.

22. Treharne GJ, Lyons AC, Hale ED, et al. Predictors of fatigue over 1 year among people with rheumatoid arthritis. Psychol Health Med 2008;13:494-504.

23. Hewlett S, Chalder T, Choy E, et al. Fatigue in rheumatoid arthritis: time for a conceptual model. Rheumatology (Oxford). Published Online First: 5 September 2010. doi:10.1093/rheumatology/keq282.

24. Department of Health. Supporting People with Long Term Conditions to Self Care - A Guide to Developing Local Strategies and Good Practice. Leeds, 2006 (270415). http://www.dh.gov.uk/en/Publicationsandstatistics/Publications/ PublicationsPolicyAndGuidance/DH_4130725 (accessed 23 September 2010)

25. Iversen MD, Hammond A, Betteridge N. Self-management of rheumatic diseases: state of the art and future perspectives. Ann Rheum Dis 2010;69:955-63.

26. Repping-Wuts $\mathbf{H}$, Hewlett $S$, van Riel $P$, et al. Fatigue in patients with rheumatoid arthritis: British and Dutch nurses' knowledge, attitudes and management. J Adv Nurs 2009;65:901-11.

27. van Kessel K, Moss-Morris R, Willoughby E, et al. A randomized controlled trial of cognitive behavior therapy for multiple sclerosis fatigue. Psychosom Med 2008;70:205-13

28. Sage N, Sowden M, Chorlton E, et al. What is the cognitive behavioural approach? In: Sage N, Sowden M, Chorlton E, Edeleanu A, eds. Cognitive Behaviour Therapy for Chronic Illness and Palliative Care. Chichester: Wiley 2008:3-9.
29. Bandura A. Self-efficacy: toward a unifying theory of behavioral change. Psychol Rev 1977;84:191-215.

30. Riemsma RP, Taal E, Rasker JJ. Group education for patients with rheumatoid arthritis and their partners. Arthritis Rheum 2003;49:556-66.

31. Hammond A, Bryan J, Hardy A. Effects of a modular behavioural arthritis education programme: a pragmatic parallel-group randomized controlled trial. Rheumatology (Oxford) 2008;47:1712-18

32. Evers AW, Kraaimaat FW, van Riel PL, et al. Tailored cognitive-behavioral therapy in early rheumatoid arthritis for patients at risk: a randomized controlled trial. Pain 2002:100:141-53.

33. Keefe FJ, Lefebvre JC, Kerns RD, et al. Understanding the adoption of arthritis self-management: stages of change profiles among arthritis patients. Pain 2000;87:303-13.

34. Arnett FC, Edworthy SM, Bloch DA, et al. The American Rheumatism Association 1987 revised criteria for the classification of rheumatoid arthritis. Arthritis Rheum 1988;31:315-24.

35. Hewlett S, Wit M, Richards P, et al. Patients and professionals as research partners: challenges, practicalities, and benefits. Arthritis Rheum 2006;55:676-80.

36. Sage N, Sowden M, Chorlton E, et al. Guided discovery: using the Socratic method. In: Sage N, Sowden M, Chorlton E, Edeleanu A, eds. Cognitive Behaviour Therapy for Chronic Illness and Palliative Care. Chichester: Wiley 2008:66-77.

37. Belza BL. Comparison of self-reported fatigue in rheumatoid arthritis and controls. $J$ Rheumatol 1995:22:639-43.

38. Fries JF, Spitz P, Kraines RG, et al. Measurement of patient outcome in arthritis. Arthritis Rheum 1980:23:137-45.

39. Hewlett S, Smith AP, Kirwan JR. Measuring the meaning of disability in rheumatoid arthritis: the Personal Impact Health Assessment Questionnaire (PI HAO). Ann Rheum Dis 2002;61:986-93.

40. de Jong Z, van der Heijde D, McKenna SP, et al. The reliability and construct validity of the RAOoL: a rheumatoid arthritis-specific quality of life instrument. Br J Rheumatol 1997;36:878-83.

41. Zigmond AS, Snaith RP. The hospital anxiety and depression scale. Acta Psychiatr Scand 1983;67:361-70.

42. Stein MJ, Wallston KA, Nicassio PM. Factor structure of the Arthritis Helplessness Index. J Rheumato/ 1988;15:427-32.

43. Hewlett S, Cockshott Z, Kirwan J, et al. Development and validation of a self-efficacy scale for use in British patients with rheumatoid arthritis (RASE). Rheumatology (Oxford) 2001;40:1221-30.

44. Buysse DJ, Reynolds CF, 3rd, Monk TH, et al. The Pittsburgh Sleep Quality Index: a new instrument for psychiatric practice and research. Psychiatry Res 1989:28:193-213.

45. Goligher EC, Pouchot J, Brant R, et al. Minimal clinically important difference for 7 measures of fatigue in patients with systemic lupus erythematosus. J Rheumatol 2008;35:635-42.

46. Sterne JA, White IR, Carlin JB, et al. Multiple imputation for missing data in epidemiological and clinical research: potential and pitfalls. BMJ 2009;338:b2393.

47. Wells G, Li T, Maxwell L, et al. Determining the minimal clinically important differences in activity, fatigue, and sleep quality in patients with rheumatoid arthritis. J Rheumatol 2007;34:280-9.

48. Tucker M, Oei TPS. Is group more cost effective than individual Cognitive Behaviour Therapy? The evidence is not solid yet. Behav Cogn Psychother 2007;35:77-91.

49. Davis MC, Okun MA, Kruszewski D, et al. Sex differences in the relations of positive and negative daily events and fatigue in adults with rheumatoid arthritis. J Pain 2010;11:1338-47.

50. Department of Health. Improving Access to Psychological Therapies Implementation Plan: National Guidelines for Regional Delivery and Contact. London: Department of Health, 2008 (286387). http://www.dh.gov.uk/prod consum dh/groups/ dh_digitalassets/@dh/@en/documents/digitalasset/dh_083168.pdf laccessed 24 Sept 2010). 